\title{
Industrialização fluminense nos séculos XIX e XX: novas pesquisas e novos saberes
}

Almir Pita Freitas Filho, Pedro Henrique Pedreira Campos e Rafael Vaz da Motta Brandão

\section{Q OpenEdition \\ 1 Journals}

\section{Edição electrónica}

URL: http://journals.openedition.org/espacoeconomia/3455

DOI: 10.4000/espacoeconomia.3455

ISSN: 2317-7837

\section{Editora}

Núcleo de Pesquisa Espaço \& Economia

\section{Refêrencia eletrónica}

Almir Pita Freitas Filho, Pedro Henrique Pedreira Campos e Rafael Vaz da Motta Brandão, « Industrialização fluminense nos séculos XIX e XX: novas pesquisas e novos saberes », Espaço e Economia [Online], 12 | 2018, posto online no dia 15 julho 2018, consultado o 24 setembro 2020. URL : http://journals.openedition.org/espacoeconomia/3455 ; DOI : https://doi.org/10.4000/ espacoeconomia.3455

Este documento foi criado de forma automática no dia 24 setembro 2020. 


\title{
Industrialização fluminense nos séculos XIX e XX: novas pesquisas e novos saberes
}

\author{
Almir Pita Freitas Filho, Pedro Henrique Pedreira Campos e Rafael Vaz da \\ Motta Brandão
}

1 A atual crise do estado do Rio de Janeiro coloca sobre os pesquisadores uma série de desafios. Para além do exercício próprio da sobrevivência, em meio à penúria da fundação estadual de amparo à pesquisa e estado de lástima das universidades fluminenses, a crise econômica, política e no campo da segurança pública são por si só objetos de estudo que precisam ser enfrentados e explicados pelos especialistas acadêmicos. Em meio a um processo de desindustrialização e reprimarização da economia, com perda de relevância do mercado interno, a economia fluminense tem perdido espaço e importância no sistema capitalista brasileiro, superado pelo epicentro do processo de acumulação - cada vez mais hipertrofiado em São Paulo - e pelos novos polos especializados na economia exportadora, como as regiões com riquezas minerais e importância agropecuária - praticamente irrelevantes no estado. Em meio aos ataques desferidos contra a Petrobrás e os desdobramentos da "Operação Lava-jato", o estado foi elevado à condição de "olho do furacão" da crise brasileira. É fácil culpar simplesmente os administradores notoriamente criminosos que estiveram à frente da condução do estado nos últimos anos ou simplesmente assinalar os abusos nas isenções fiscais às grandes empresas. Apesar da validade parcial dessas explicações, um exame mais cuidadoso do processo histórico, que se detenha nas condições estruturais da economia do estado, vai verificar sua fragilidade em meio ao padrão de acumulação predominante hoje no capitalismo brasileiro e um caráter cada vez mais periférico representado pela federação fluminense na economia nacional.

2 No entanto, nem sempre foi assim. A região geográfica que hoje compõe o estado do Rio de Janeiro - que só tomou essa forma administrativa com a fusão procedida pela ditadura, em 1975 - já foi o polo dinâmico da economia brasileira, seja no período dourado da produção de café no Vale do Paraíba, seja nos primórdios do processo 
brasileiro de industrialização. Ao longo de todo o século XX, desde os anos 1920 quando estatisticamente a produção fabril fluminense e carioca foi superada pela paulista - o Rio dispôs da condição de segundo principal centro industrial brasileiro, sediando plantas fabris relevantes para o processo nacional de industrialização, como a usina siderúrgica de Volta Redonda, a Fábrica Nacional de Motores, a planta química da Bayer, a fábrica de cimento Portland em Guaxindiba, as usinas termonucleares de Angra dos Reis, a refinaria Duque de Caxias, os principais estaleiros da indústria naval brasileira, o polo metal-mecânico implantado nas últimas décadas no Sul Fluminense (em Resende e nos municípios vizinhos), as confecções serranas centradas em Nova Friburgo, dentre outros empreendimentos de monta.

3 Apesar da estagnação econômica do estado, o Rio continuou a ser um dos principais polos universitários e de pesquisa do país. Assim, nas últimas décadas houve uma expansão dos programas de pós-graduação, inclusive em regiões antes desguarnecidas mesmo de cursos superiores públicos. Com isso, multiplicaram-se pesquisas com novas perspectivas e sobre regiões antes pouco ou nada estudadas. Universidades situadas nas franjas da região metropolitana do Rio de Janeiro, como a Faculdade de Formação de Professores da Uerj, em São Gonçalo, e a UFRRJ, em Seropédica e Nova Iguaçu, criaram programas de pós-graduação de História e desenvolveram estudos sobre os seus municípios e regiões do entorno dessas instituições. Isso propiciou estudos renovados inclusive sobre as fábricas e regiões industriais dessas cidades.

4 Como resultado dessa renovação de estudos apresentamos o dossiê Industrialização fluminense nos séculos XIX e XX. São oito artigos resultantes de pesquisas recentemente desenvolvidas ou ainda em desenvolvimento e que trazem um novo olhar sobre a indústria do estado do Rio de Janeiro, em particular a situada em regiões mais periféricas e nos arrabaldes do núcleo urbano carioca. É uma feliz conveniência esse dossiê ser publicado em uma revista de Geografia Econômica, visto que a localização espacial dos casos analisados percorre diversos municípios e dá um quadro da indústria distribuída no estado. Os estudos abrangem regiões como Paracambi, Nova Iguaçu, São Gonçalo, Magé, Niterói e a zona portuária da cidade do Rio de Janeiro. Assim, mesmo escritos basicamente por historiadores, os artigos publicados nesse ensaio possuem um forte potencial de diálogo com a Geografia Econômica, em particular a dedicada à industrialização fluminense.

5 Os textos aqui publicados são oriundos em geral de pesquisas de mestrado e doutorado desenvolvidas em programas de História distribuídos pelo estado. Assim, o primeiro artigo é de autoria de Cristiane Furtado e versa sobre a fábrica de tecidos de Paracambi, estabelecida na região no período do Império e analisada no texto ao longo de sua trajetória na segunda metade do século XIX. Trata-se de um grande empreendimento industrial que ganhou apoiou do imperador e seria uma símbolo da modernidade e do progresso na região mais próspera do país, a região do Vale do Paraíba fluminense, dominada pelos cafezais que faziam a prosperidade do Império.

6 Também situado cronologicamente na segunda metade do século XIX, o artigo de Thiago Mantuano se debruça sobre a região portuária do Rio de Janeiro. $O$ autor indica como, para além de um simples entreposto comercial, o porto constituía no período um importante polo industrial, no qual havia o beneficiamento, ensacamento e processamento de vários produtos, além de atividades de indústrias importantes, como a naval, os moinhos etc. Acessando fontes primárias preciosas, o texto mostra como a 
zoa portuária era em si uma importante região industrial e no entorno da mesma se situavam diversas fábricas que tinham suas atividades ligadas à atividade portuária.

$7 \quad 0$ artigo de Luciana Wollmann problematiza a indústria da cidade de Niterói no início do século XX, mostrando como a região norte do município que constituía a capital do estado do Rio de Janeiro era no período um dos principais polos industriais do país, com fábricas que tinham continuidade no município de São Gonçalo. A autora problematiza além das indústrias instaladas na região a formação da classe trabalhadora no chão da fábrica e nos bairros industriais do município, como Barreto e Fonseca. Analisando a experiência dos operários, ela indica os traços constitutivos e as organizações desses trabalhadores.

8 Dois artigos se debruçam sobre a industrialização da cidade vizinha a Niterói, São Gonçalo. Esse já foi um dos municípios com produção industrial mais importante do estado e do país. A cidade contava com diversificada indústria e protagonismo econômico, em especial na primeira metade do século XX, como mostra o artigo de José Luís Honorato Lessa. $\mathrm{O}$ autor se detém acerca de vários empreendimentos e fábricas existentes em São Gonçalo, mostrando a diversidade dos tipos fabris desse que é o segundo município mais populoso atualmente do estado do Rio de Janeiro. Acessando fontes municipais, o autor traça um rico painel da indústria existente em São Gonçalo e problematiza o processo de estagnação industrial da cidade.

9 Também versando sobre São Gonçalo, mas se detendo mais em um setor específico, o texto de Rafael Vaz da Motta Brandão centra esforços na análise da indústria cimenteira, que possuía no município a grande planta industrial da fábrica de Cimento Portland, em Guaxindiba. A unidade constituía um dos maiores empreendimentos produtivos da primeira metade do século XX no Brasil, já representando não mais a predominante indústria de bens de consumo não-duráveis típicas das primeiras três décadas da industrialização do país no século, mas uma fábrica que produzia um bem de produção, usado na indústria da construção civil. Trata-se de uma unidade que abastecia a então capital da República, em franco processo de crescimento e urbanização e todas as obras públicas e habitacionais tocadas na cidade e no estado no período.

10 A referida indústria da construção civil, principalmente da cidade do Rio de Janeiro, é analisada em texto de Pedro Campos. $O$ artigo percorre a trajetória do setor ao longo do século XX, centrando a análise sobre a indústria da construção pesada, responsável pelos empreendimentos de infraestrutura e obras públicas. O ramo é entendido como uma atividade industrial e é indicada a sua importância para o setor fabril no estado, tendo em vista as grandes cidades ali existentes, em particular o Rio de Janeiro, e os diversos projetos de infra-estrutura levados a cabo na urbe, em particular no período da ditadura civil-militar (1964-1988).

11 Deslocando-se da borda Leste da baía de Guanabara e da cidade do Rio de Janeiro, a região que despontou como principal polo industrial do grande Rio a partir de meados do século XX foi a Baixada Fluminense, seguindo as linhas da avenida Brasil. dos trens suburbanos e das rodovias Presidente Dutra e Washington Luís. Assim, o município de Magé, com seu amplo arco de rios que descem a serra e desembocam na baía de Guanabara, foi, em por conta de suas condições geográficas adequadas, um polo industrial importante, em particular no setor têxtil. Assim, o artigo de Felipe Ribeiro analisa as fábricas têxteis da região no período da II Guerra Mundial e a luta dos 
trabalhadores industriais e também os rurais no município, tendo em vista o caráter misto da economia local e das próprias unidades produtivas ali existentes.

Por fim, o texto de Carolina Bittencourt analisa o caso particular da fábrica de canetas Compactor, situada em Nova Iguaçu e fundada por iniciativa de imigrantes alemães vindos ao Brasil após o fim da II Guerra Mundial. Trata-se de um polo produtivo importante da Baixada Fluminense, em meio a outras unidades produtivas relevantes, como o complexo químico da Bayer, situado em Belford Roxo. A autora analisa as ações da fábrica no ambiente da cidade, mostrando a atuação na construção de vilas operárias e serviços para as famílias operários, como mecanismo de controle e paternalismo sobre a vida dos trabalhadores.

Os textos desse dossiê trazem estudos recentes e renovados sobre o processo de industrialização fluminense. Sem realizar uma visão genérica sobre o problema ou desenvolver um olhar excessivamente quantitativo e impessoalizado sobre o assunto, os artigos tentam verificar e analisar as ações dos sujeitos históricos envolvidos nesse processo, sejam os empresários, sejam os trabalhadores. Com isso, acreditamos que o dossiê contribui para renovar e complexificar a visão que temos sobre o processo histórico da industrialização fluminense. Com ele podemos entender melhor também como se deu a trajetória da indústria na região e como chegamos ao processo atual de estagnação e crise econômica do estado.

Rio de Janeiro, abril de 2018.

\section{AUTORES}

\section{ALMIR PITA FREITAS FILHO}

Professor do Instituto de Economia da UFRJ. Correio eletrônico: almir@ie.ufrj.br.

\section{PEDRO HENRIQUE PEDREIRA CAMPOS}

Professor do Departamento de História e Relações Internacionais da UFRRJ. Correio eletrônico: phpcampos@yahoo.com.br.

\section{RAFAEL VAZ DA MOTTA BRANDÃO}

Professor da Faculdade de Formação de Professores da Uerj. Correio eletrônico:

rafabrandao@uol.com.br. 